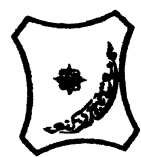

Bayero Journal of Pure and Applied Sciences, 10(1): 115 - 127

Received: October, 2016

Accepted: May, 2017

ISSN $2006-6996$

\title{
DFT, RHF AND MP2 BASED STUDY OF THE THERMODYNAMIC, ELECTRONIC AND NON-OPTICAL PROPERTIES OF DNA NUCLEOBASES
}

\author{
${ }^{1}$ Gidado, A.S., ${ }^{2}$ Salihu Abubakar and ${ }^{3}$ Shariff, M.A. \\ ${ }^{1}$ Department of Physics, Bayero University Kano PMB 3011 \\ ${ }^{2}$ Post Graduate Student, Department of Physics Bayero University Kano \\ ${ }^{3}$ Department of Physics, Federal College of Education Katsina P.M.B 2041 \\ Email: asgidado.phy@buk.edu.ng Phone : 08028276213
}

ABSTRACT

Deoxyribonucleic acid or DNA is a molecule that contains the instructions an organism needs to develop, live and reproduce. These instructions are found inside every cell, and are passed down from parents to their children. In this study, the DNA nucleobases, that is. Adenine (A), Guanine (G), Cytosine(C) and Thymine (T) have been investigated by employing quantum chemical methods calculation. The thermodynamic parameters such as entropy, enthalpy, heat capacity and zero point vibrationional energy, non optical linear properties (dipole moment and mean polarizability) and Mullikan charges were calculated using Restricted Hartree-Fock (RHF), Moller-Plesset Second Order Perturbation Theory (MP2) and Density FuTheory (DFT), B3LYP and LSDA methods with 321G, 3-21+G and 6-31G basis sets. In addition, HOMO-LUMO energy gap of each of the molecules was calculated. The high value of HOMO-LUMO energy gap indicates the high stability of the molecules in chemical reaction. Of the four molecules, guanine has the highest value of HOMOLUMO energy gap which implies that it is the most stable molecule in chemical reaction. The values of the dipole moment obtained were in agreement with the experimental values. For instance, the dipole moment of guanine at B3LYP/6-31G was calculated as 7.2D while the experimental value is 7.1D. Gaussian 03 package was used to perform all the calculations. Results from comparison of the DFT, MP2 and RHF methods shows close results and can be seen to support one another.

Key: DNA, Nucleobases, HOMO-LUMO, DFT, RHF and MP2

\section{INTRODUCTION}

Nucleic acids are essential materials found in all living organisms. They perform a variety of crucial functions in organisms. Their main function is to maintain and transmit the genetic code. This information is stored in the form of long polymer chains. Although the information they carry is one-dimensional, it is essential to understand the 3D structure of nucleic acids. This 3D structure dictates their organization, functions and interactions with proteins. The two nucleic acids are deoxyribonucleic acid (DNA) and ribonucleic acid (RNA). The main difference between DNA and RNA is the sugar present in the molecules. While the sugar present in a RNA molecule is ribose, the sugar present in a molecule of DNA is deoxyribose. Deoxyribose is the same as ribose, except that the former has one more $\mathrm{OH}$. While they have significantly different structures, we can describe both DNA and RNA as polynucleotides (Neuman, 1999).

Each nucleotide contains a phosphate group, a sugar group and a nitrogen base. The group that gives each nucleic acid unit its specificity is the organic base. The nucleotide bases found in nuclei acids are related either to the purine ring system or to the pyrimidine ring system.

In DNA, we find principally four different bases: Adenine $(A)$, Guanine $(G)$, Cytosine $(C)$ and Thymine ( $T$ ). The first two are derived from purine whereas the remaining two are derived from pyrimidine. In RNA we find principally four different bases: adenine, guanine and cytosine as in DNA. The fourth base in RNA, however, is not thymine but instead the pyrimidine-derived base, Uracil (U).The chemical structures for each of the four bases are shown below in fig.1.0 (Bryce and Pacini, 1998).<smiles>Nc1ncnc2[nH]cnc12</smiles>

Adenine<smiles>Nc1nc2[nH]c(N)nc2c(=O)[nH]1</smiles>

Guanine 


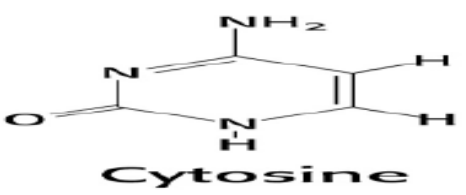

Fig.1.0 DNA bases

James Watson and Francis Crick proposed a structure for the DNA molecule that suggested the basic mechanism of DNA replication. The model proposes that DNA is composed of two strands of DNA running anti-parallel to each other. The two strands are held together by weak hydrogen bonds between the nitrogenous bases. In the Watson-crick DNA base pairing model, a purine always binds with a pyramidine. However, each purine binds to one particular type of pyramidine. Adenine (A) binds to thymine $(T)$ while guanine $(G)$ binds to cytosine $(C)$. However, in RNA uracil(U) is substituted for thymine $(T)$. This base pairing is referred to as complementary base pairing, hence the base pairs are called complementary base pairs. The base pairs are bound by hydrogen bonds, although the number of $\mathrm{H}$ bonds differs between base pairs. G-C base pairs are bound by three (3) hydrogen bonds while A-T base pairs are bound by two (2) hydrogen bonds.

Watson-Crick base pairing is of very great importance as it is a deciding factor in DNA replication. It ensures that pairs form between complementary bases only. The formation of base pairs between two noncomplementary bases results in gene mutations which can be detrimental to development of an organism.

Similar to the way the order of letters in the alphabet can be used to form a word, the order of nitrogen bases in a DNA sequence forms genes, which in the language of the cell, tells how to make proteins.

Hydrogen bonds that hold together the two strands of nucleotides in DNA have been the main scope of many experimental and theoretical investigations for three decades. The importance of this molecular interaction is due to its role in DNA replication and complementarity of nucleic acid bases which is the cornerstone of the genetic code (Espejo and Gonzalez, 2007).

Hydrogen bonded and stacked nucleic acid bases adenine $(A)$, thymine $(T)$, guanine $(G)$ and cytosine (C) - play a pivotal role in the structure and function of DNA. They influence the formation of the secondary structure of biopolymers, the interaction with drugs and proteins, the conformational dynamics and polymorphism of DNA (Neidle, 1994). Bases in a DNA molecule are involved mainly in two types of interactions. The first one includes the formation of the Watson-Crick base pairs due to hydrogen bonding between adenine and thymine (A-T pair) and guanine and cytosine (G-C pair). These dimers are mainly stabilized by electrostatic interactions. The second type of interactions is represented by stacking between neighboring bases along the vertical axis of a double-stranded biopolymer. The stacking interactions mainly originate from dispersion interactions between two parallel bases. Overall $\mathrm{H}$-bonded pairs of nucleic acid bases are more favored on the potential energy surface than stacked pairs, but both interactions are of equal importance in nucleic acids.

The structure of hydrogen bonded and stacked dimers of nucleic acid bases were extensively investigated using different methods. The different nature of stabilization forces in these two types of dimers cause different approaches to their theoretical investigation. The electrostatic origin of the hydrogen bonds allows to study $\mathrm{H}$-bonded complexes of bases with a wide range of quantum chemical and force field methods (Hobza et. al, 1997), and, therefore, these calculations were easily extended from base pairs to trimers, tetramers, etc. , studying effects of cooperativity of interactions, different ways of hydrogen bonding, non-planarity of base pairs, etc.

The significant contribution of dispersion forces into stacking interactions is a considerable challenge for computational methods, since a correct description of dispersion requires an adequate inclusion of electron correlation and an application of extended basis sets. The computationally least expensive $a b$ initio method covering electron correlation is second order MollerPlesset perturbation theory (MP2), which can be applied to molecular systems of the size of DNA base pairs. However, for a quantitative accurate description higher level treatment of correlation in combination with large basis sets is required, which limits these calculations to system sizes containing few atoms. Fortunately, the effects of higher level treatment of correlation and increasing basis sets have opposite effect on the stabilization energies. Exploiting this error compensation, a cheaper computational model utilizing MP2 and the 6-31G basis set has been proposed for the study of base pair stacking, providing an accurate and reliable description of dispersion interactions. However, MP2 calculations are considerably more time and resource consuming as compared to HF and DFT methods. This limits the applicability of this method for systems larger than dimers of bases.

Empirical force field methods are widely used for the simulation of the structure and dynamics of large fragments of DNA and it has been demonstrated, that several force fields describe hydrogen bonding and stacking interactions between bases very accurately (Hobza et. al, 1997). However, force fields do not cover the polarization of DNA bases due to interaction with each other. They also failed to reproduce some structural effects like pyramidalization of the amino group, conformational flexibility of the pyrimidine rings in DNA bases, etc. (Shishkin et. $a l, 2008)$. However, the application of MP2 calculations for the investigation of the geometry of stacked dimers and especially of larger stacked complexes is limited because of their high computation costs (Hobza et. al, 1997). 
A quantum chemical method for the calculation of large molecules has been developed on the basis of an approximation to density functional theory. This method can be described as a general extension of tight-binding methods to charge self-consistency. All parameters of this model are calculated from DFT, and the method is, therefore, called a self-consistent charge, density functional tight binding method (SCCDFTB). Application of this method to various organic molecules, polypeptides, $\mathrm{H}$-bonded complexes and DNA bases (Shishkin et. al, 2008) revealed good agreement in energetics, geometrical parameters and vibrational properties between SCC-DFTB and experimental data and results of DFT and postHartree-Fock methods. This method was complemented with an empirical dispersion energy correction (SCC-DFTB-D method) in order to reproduce the interaction energy of stacked nucleobases. The results of the calculations demonstrated very good agreement between SCCDFTB-D and MP2 data for the energy of hydrogen bonding and stacking interactions for a wide range of nucleic acid base pairs. Another important advantage of this method is its very high computational efficiency.

\section{THEORETICAL BACKGROUND \\ Density Functional Theory (DFT)}

The density functional theory is a computational quantum mechanical modeling method used in Physics, Chemistry and Material science to investigate the electronic structure (principally the ground state) of many-body systems, in particular atoms, molecules and the condensed phases. It is presently the most successful (and also the most promising) approach to compute the electronic structure of matter. Its applicability ranges from atoms, molecules and solids to nuclei and quantum and classical fluids. DFT predicts a great variety of molecular properties: molecular structures, vibrational frequencies, atomization energies, ionization energies, electric and magnetic properties, reaction paths etc. Beyond Hartree-Fock approximation, the great advantage of density functional theory stems from the inference of correlation effects. More exactly, the density functional approach is based on a strategy of modelling the electron correlation via general functionals of the electron density. Following the work by Kohn and Sham, the approximate functionals employed by current DFT methods separate the electronic energy into several terms (Robert et. al, 2002).

$\mathrm{E}=E_{T}+E_{V}+E_{J}+E_{X C}$

where $E_{T}$ is the kinetic energy term, $E_{V}$ includes terms describing the potential energy of the nuclear-electron attraction and of the repulsion between pairs of nuclei, $E_{J}$ is the electron-electron repulsion term, and $E_{X C}$ is the exchange-correlation term and includes the remaining part of the electron-electron interactions. The energy sum $E_{T}+E_{V}+E_{J}$ corresponds to the classical energy of the charge distribution $\rho$. The exchange-correlation term $E_{X C}$ accounts for the exchange energy arising from the antisymmetry of the quantum wavefunctions and for the dynamic correlation in the motions of individual electrons. Hohenberg and Kohn demonstrated that $E_{X C}$ is entirely determined by the electron density:

$E_{X C}(\rho)=\int f\left(\rho_{\alpha}(r), \quad \rho_{\beta}(r), \quad \nabla \rho_{\alpha}(r), \quad \nabla \rho_{\beta}(r) \quad\right) d^{3}(r)$

(2)

where $\rho_{\alpha}, \rho_{\beta}$ are referring to the corresponding $a, \beta$ spin densities.

$E_{X C}$ is usually divided into components, referred to as the exchange and correlation parts, but actually corresponding to the same-spin and mixed-spin interactions, respectively:

$E_{X C}(\rho)=E_{X}(\rho)+E_{C}(\rho)$

(3)

HOMO-LUMO Energy Gap: Molecular orbital (MO) is a mathematical function describing the wave-like behavior of an electron in a molecule. This function can be used to calculate chemical and physical properties such as the probability of finding an electron in any specific region. HOMO and LUMO are acronyms for highest occupied molecular orbital and lowest unoccupied molecular orbital respectively. The difference between HOMO and LUMO is termed the HOMO-LUMO gap. HOMO and LUMO are sometimes referred to as Frontier orbitals. The energy of the HOMO-LUMO gap can tell us about what wavelengths a compound can absorb. In fact, it is quite common to extract trends in molecular behavior based on simple MO properties. For example, molecules with large HOMO-LUMO gaps are generally stable and unreactive; while those with small gaps are generally reactive (Gang and Charles, 2007).

HOMO-LUMO gap $=E_{\text {LUMO }}-E_{\text {HOMO }}$

\section{Dipole Moment and Polarizability}

The charge redistribution that occurs when a particle is exposed to an electric field is characterized by a set of constants called polarizabilities. The new charge distribution can be written in terms of electric multipole moments. The lowest-order moment of a neutral particle is a dipole moment $\mu$. In a uniform electric field, $\mathrm{E}$ the dipole moment of the particle is conveniently written as

$\mu=\mu_{o}+a E+\frac{1}{2} \beta E^{2}+\frac{1}{6} \gamma E^{3}+$

The term $\mu_{o}$ represents the permanent dipole moment. The polarizability $a$ is a second-rank Cartesian tensor that characterizes the lowest-order induced dipole moment in a species. The hyperpolarizabilities $\beta$ and $Y$ represent third-and fourth-rank Cartesian tensors.

For calculating the total dipole moment the mathematical expression is defined as:

$(\mu)=\left(\mu_{x}^{2}+\mu_{y}^{2}+\mu_{z}^{2}\right)^{1 / 2}$

Polarizabilities are helpful in determining the electronic structure of atoms, molecules, and clusters (Keith and Vitaly, 1997). 
BAJOPAS Volume 10 Number 1 June, 2017

\section{METHODOLOGY}

This work employed computational methods to carry out all the computations. The molecular structures of Guanine, Cytosine, Adenine and Thymine bases were obtained from Ligand expo database. Ligand expo (formerly Ligand Depot) is an online database which provides chemical and structural information about small molecules (so-called ligands) within the structure entries of the Protein Data Bank (PDB).Tools were provided to search the PDB dictionary for chemical components to identify structure entries containing particular small molecules and the 3D structures of the small molecule components were downloaded from the PDB entry (Feng et. al, 2004).

All calculations were performed using Windows Version Gaussian 03 Package. The molecular structures of Adenine, Cytosine, Guanine and Thymine were optimized using RHF, DFT and MP2 methods with the Gaussian 03 package program. Different basis sets such as 3-21G3-21+G, 6-31G and 6-31+G were used.

The Gaussian program took information from the starting geometry and then evaluated a new geometry that is closer to a minimum in the potential energy surface than the previous geometry. The information used includes the energy, the first derivative of the energy with respect to changes in the position of the atoms. This process was repeated until the maximum number of steps was reached or the calculation was satisfied that it is close enough to a minimum. When the program was satisfied that a minimum was found, then the geometry was said to be converged i.e. a stable end point is reached. Geometric parameters such as the optimized bond lengths and bond angles were obtained.

The vibrational runs used the optimized structure of the molecule. Some thermodynamics properties of each of the molecules such as enthalpy, heat capacity, entropy and zero point vibration energy were obtained from the vibrational runs. It involved the calculation of the Hessian matrix.

HOMO and LUMO energies of Adenine, Cytosine, Guanine and Thymine were calculated by RHF, DFT and MP2 methods with the corresponding basis sets. The HOMO-LUMO energy gaps of each of the molecules for all the methods used were calculated using the difference between the HOMO-LUMO energy as shown in equation (2.4).

\section{RESULTS AND DISCUSSION THERMODYNAMIC PROPERTIES OF THE NUCLEOBASES}

Some of the thermodynamic properties of adenine, cytosine, guanine and thymine calculated in this work includes enthalpies, heat capacities, entropies and zero point vibration energies. The properties as shown in Tables 1 to 4 were calculated at different levels of theory (RHF,DFT and MP2). The basis sets used at each level of theory are 3-21G, 3-21+G and 6-31G.

\section{Enthalpy}

It can be seen from Tables 1 to 4 that at each level of theory with the different basis sets, that guanine has the highest values of enthalpies while cytosine has the lowest values. The order is indicated as follows: $\mathrm{G}>\mathrm{T}>\mathrm{A}>\mathrm{C}$. It is also indicated that there is a very strong agreement between the values of enthalpies obtained by the different methods together with the basis sets used. The highest value of enthalpy (84.761Kcal /Mol) was obtained at RHF/6-31G while the lowest value $(57.298 \mathrm{Kcal} / \mathrm{Mol})$ was obtained at LSDA/3-21+G.

\section{Heat Capacity}

Guanine is also observed to have the highest values of heat capacities at each level of theory with all the basis sets used while cytosine has the lowest values. However, the order of greatness is a bit different from the case obtained with the enthalpy. The order is as follows: $\mathrm{C}>\mathrm{A}>\mathrm{T}>\mathrm{C}$. The results in the Tables also show the strong agreement between the values of heat capacities obtained by the different methods. The highest value of heat capacity (30.291 Cal/MolKelvin) was obtained at LSDA/3-21G while the lowest value (18.801 Cal/Mol-Kelvin) was obtained at MP2/321G.

Entropy(S): There is also a strong agreement between the values of entropies obtained by the different methods. The molecule with the highest entropy is guanine while cytosine has the lowest entropy.

Zero Point Vibration Energy (ZPVE): This is the energy of vibration of a molecule at absolute zero $(0 K)$. It can be seen from the Tables that guanine has the highest values of ZPVE while cytosine has the lowest values. The order is indicated as follows: $\mathrm{G}>\mathrm{T}>\mathrm{A}>\mathrm{C}$. It is also indicated that there is a very strong agreement between the values of ZPEs obtained by the different methods together with the basis sets used. The highest value of ZPVE (88.317Kcal /Mol) was obtained at MP2/3-21+G while the lowest value $(53.64915 \mathrm{Kcal} / \mathrm{Mol})$ was obtained at LSDA/3-21+G.

Table 1: RHF Method

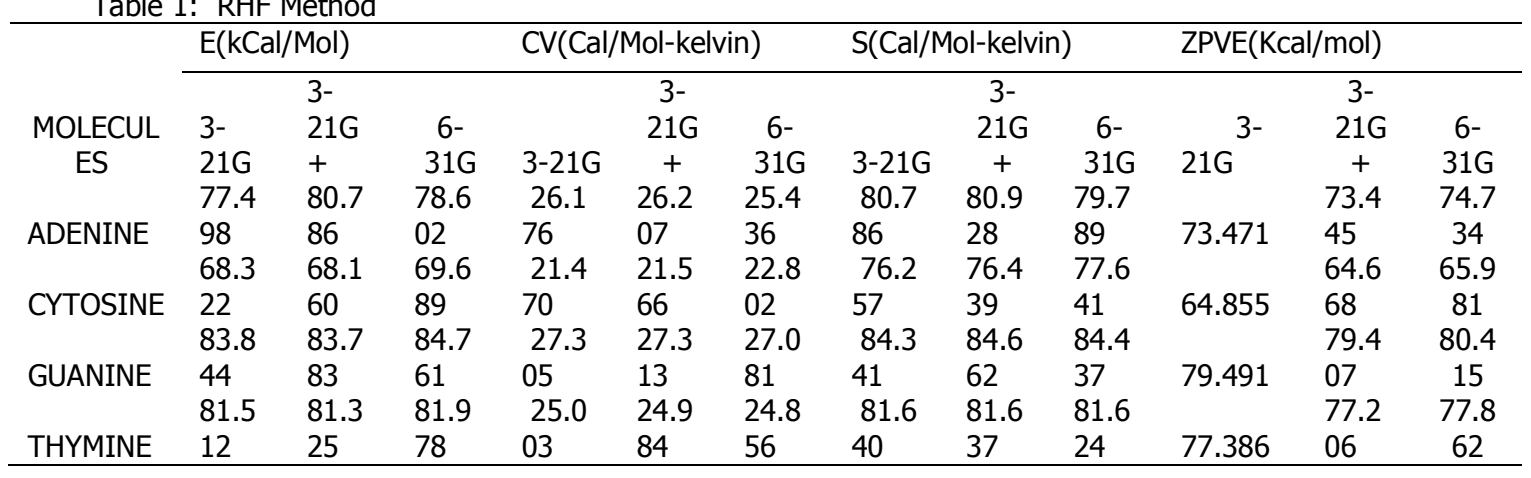


BAJOPAS Volume 10 Number 1 June, 2017

Table 2: DFT (LSDA) Method

\begin{tabular}{|c|c|c|c|c|c|c|c|c|c|c|c|c|}
\hline \multirow[b]{2}{*}{$\begin{array}{l}\text { MOLECUL } \\
\text { ES }\end{array}$} & \multicolumn{3}{|c|}{$\mathrm{E}(\mathrm{kCal} / \mathrm{Mol})$} & \multicolumn{3}{|c|}{ CV(Cal/Mol-kelvin) } & \multicolumn{3}{|c|}{ S(Cal/Mol-kelvin) } & \multicolumn{3}{|c|}{ ZPVE(Kcal/mol) } \\
\hline & $\begin{array}{l}3-21 \\
G\end{array}$ & $\begin{array}{l}3- \\
21 \mathrm{G}+\end{array}$ & $\begin{array}{c}6- \\
31 G\end{array}$ & $3-21 G$ & $\begin{array}{l}3- \\
21 \mathrm{G}+\end{array}$ & $\begin{array}{c}6- \\
31 G\end{array}$ & $3-21 G$ & $\begin{array}{l}3- \\
21 \mathrm{G}+\end{array}$ & $\begin{array}{l}6- \\
31 G\end{array}$ & $3-21 G$ & $\begin{array}{l}3- \\
21 \mathrm{G}+\end{array}$ & $\begin{array}{l}6- \\
31 G\end{array}$ \\
\hline ADENINE & $\begin{array}{l}71.24 \\
5\end{array}$ & $\begin{array}{l}71.29 \\
0\end{array}$ & $\begin{array}{l}72.01 \\
3\end{array}$ & $\begin{array}{l}27.3 \\
72\end{array}$ & $\begin{array}{l}27.40 \\
8\end{array}$ & $\begin{array}{l}26.87 \\
1\end{array}$ & $\begin{array}{l}83.9 \\
91\end{array}$ & $\begin{array}{l}85.15 \\
7\end{array}$ & $\begin{array}{l}81.67 \\
6\end{array}$ & $\begin{array}{l}66.8 \\
25\end{array}$ & $\begin{array}{l}66.80 \\
2\end{array}$ & $\begin{array}{l}67.84 \\
5\end{array}$ \\
\hline CYTOSINE & $\begin{array}{l}63.07 \\
8\end{array}$ & $\begin{array}{l}63.00 \\
4\end{array}$ & $\begin{array}{l}64.22 \\
8\end{array}$ & $\begin{array}{l}24.1 \\
67\end{array}$ & $\begin{array}{l}24.20 \\
2\end{array}$ & $\begin{array}{l}25.59 \\
6\end{array}$ & $\begin{array}{l}81.3 \\
70\end{array}$ & $\begin{array}{l}80.88 \\
0\end{array}$ & $\begin{array}{l}82.16 \\
8\end{array}$ & $\begin{array}{l}58.9 \\
42\end{array}$ & $\begin{array}{l}81.37 \\
0\end{array}$ & $\begin{array}{l}59.90 \\
0\end{array}$ \\
\hline GUANINE & $\begin{array}{l}77.74 \\
0\end{array}$ & $\begin{array}{l}77.76 \\
8\end{array}$ & $\begin{array}{l}78.43 \\
7\end{array}$ & $\begin{array}{l}30.2 \\
91\end{array}$ & $\begin{array}{l}30.26 \\
6\end{array}$ & $\begin{array}{l}30.06 \\
7\end{array}$ & $\begin{array}{l}87.7 \\
56\end{array}$ & $\begin{array}{l}88.12 \\
9\end{array}$ & $\begin{array}{l}86.89 \\
8\end{array}$ & $\begin{array}{l}72.8 \\
50\end{array}$ & $\begin{array}{l}72.85 \\
4\end{array}$ & $\begin{array}{l}73.63 \\
3\end{array}$ \\
\hline THYMINE & $\begin{array}{l}75.54 \\
5 \\
\end{array}$ & $\begin{array}{l}75.46 \\
0\end{array}$ & $\begin{array}{l}75.92 \\
6 \\
\end{array}$ & $\begin{array}{l}27.2 \\
30\end{array}$ & $\begin{array}{l}27.16 \\
7\end{array}$ & $\begin{array}{l}27.00 \\
0\end{array}$ & $\begin{array}{c}83.7 \\
10\end{array}$ & $\begin{array}{l}83.28 \\
8 \\
\end{array}$ & $\begin{array}{l}83.38 \\
3 \\
\end{array}$ & $\begin{array}{l}71.0 \\
51\end{array}$ & $\begin{array}{l}71.01 \\
3\end{array}$ & $\begin{array}{l}71.49 \\
5\end{array}$ \\
\hline
\end{tabular}

Table 3: DFT (B3LYP) Method

\begin{tabular}{|c|c|c|c|c|c|c|c|c|c|c|c|c|}
\hline \multirow{3}{*}{$\begin{array}{l}\text { MOLECUL } \\
\text { ES }\end{array}$} & \multicolumn{3}{|c|}{$\mathrm{E}(\mathrm{kCal} / \mathrm{Mol})$} & \multicolumn{3}{|c|}{ CV(Cal/Mol-kelvin) } & \multicolumn{3}{|c|}{ S(Cal/Mol-kelvin) } & \multicolumn{3}{|c|}{ ZPVE(Kcal/mol) } \\
\hline & 3- & 3- & $6-$ & & 3- & $6-$ & & 3- & 6- & & $3-$ & $6-$ \\
\hline & $\begin{array}{l}21 \mathrm{G} \\
72.98\end{array}$ & $\begin{array}{l}21 \mathrm{G}+ \\
73.04\end{array}$ & $\begin{array}{l}31 \mathrm{G} \\
73.83\end{array}$ & $\begin{array}{l}3-21 \mathrm{G} \\
27.9\end{array}$ & $\begin{array}{l}21 \mathrm{G}+ \\
27.95\end{array}$ & & $\begin{array}{l}3-21 \mathrm{G} \\
83.6\end{array}$ & $\begin{array}{l}21 \mathrm{G}+ \\
83.91\end{array}$ & $\begin{array}{c}31 \mathrm{G} \\
82.36\end{array}$ & & $\begin{array}{l}21 \mathrm{G}+ \\
68.57\end{array}$ & \\
\hline ADENINE & $\begin{array}{l}0 \\
64.83\end{array}$ & $\begin{array}{l}6 \\
64.77\end{array}$ & $\begin{array}{l}5 \\
65.43\end{array}$ & $\begin{array}{l}67 \\
24.63\end{array}$ & $\begin{array}{l}9 \\
24.63\end{array}$ & $\begin{array}{l}8 \\
24.14\end{array}$ & $\begin{array}{l}91 \\
80.3\end{array}$ & $\begin{array}{l}3 \\
80.55\end{array}$ & $\begin{array}{l}4 \\
79.70\end{array}$ & $\begin{array}{l}30 \\
60.7\end{array}$ & $\begin{array}{l}9 \\
80.37\end{array}$ & $\begin{array}{l}9 \\
61.44\end{array}$ \\
\hline CYT & $\begin{array}{l}1 \\
78.97\end{array}$ & $\begin{array}{l}6 \\
79.04\end{array}$ & $\begin{array}{l}6 \\
79.74\end{array}$ & $\begin{array}{l}9 \\
28.9\end{array}$ & $\begin{array}{l}6 \\
28.88\end{array}$ & $\begin{array}{l}3 \\
28.75\end{array}$ & $\begin{array}{l}73 \\
85.6\end{array}$ & $\begin{array}{l}3 \\
85.65\end{array}$ & $\begin{array}{l}1 \\
85.54\end{array}$ & $\begin{array}{c}24 \\
74 .\end{array}$ & $\begin{array}{l}3 \\
74.43\end{array}$ & $\begin{array}{l}8 \\
75.17\end{array}$ \\
\hline GUA & $\begin{array}{l}5 \\
76.94\end{array}$ & $\begin{array}{l}4 \\
76.88\end{array}$ & $\begin{array}{l}0 \\
77\end{array}$ & $\begin{array}{l}71 \\
25.8\end{array}$ & $\begin{array}{l}3 \\
25.78\end{array}$ & $\begin{array}{l}0 \\
25\end{array}$ & $\begin{array}{l}11 \\
82.12\end{array}$ & $\begin{array}{l}5 \\
81.74\end{array}$ & $\begin{array}{l}1 \\
82 .\end{array}$ & $\begin{array}{l}66 \\
72.7\end{array}$ & $\begin{array}{l}6 \\
72.69\end{array}$ & $\begin{array}{l}0 \\
73.12\end{array}$ \\
\hline THYMINE & 7 & 6 & 4 & 88 & 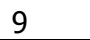 & 2 & 6 & 3 & 6 & 15 & 7 & 0 \\
\hline
\end{tabular}

Table 4 : MP2 Method

\begin{tabular}{cllllllllllll}
\hline & \multicolumn{1}{l}{$\mathrm{E}(\mathrm{kCal} / \mathrm{Mol})$} & \multicolumn{4}{c}{$\mathrm{CV}(\mathrm{Cal} /$ Mol-kelvin) } & \multicolumn{3}{c}{$\mathrm{S}(\mathrm{Cal} /$ Mol-kelvin) } & \multicolumn{3}{c}{ ZPVE(Kcal/mol) } \\
\cline { 2 - 14 } MOLECUL & $3-$ & $3-$ & $6-$ & & $3-$ & $6-$ & & $3-$ & $6-$ & & $3-$ & $6-$ \\
ES & $21 \mathrm{G}$ & $21 \mathrm{G}+$ & $31 \mathrm{G}$ & $3-21 \mathrm{G}$ & $21 \mathrm{G}+$ & $31 \mathrm{G}$ & $3-21 \mathrm{G}$ & $21 \mathrm{G}+$ & $31 \mathrm{G}$ & $3-21 \mathrm{G}$ & $21 \mathrm{G}+$ & $31 \mathrm{G}$ \\
& 73.25 & 72.37 & 73.01 & 28.42 & 26.84 & 27.16 & 87.3 & 82.79 & 82.93 & 68.5 & 68.08 & 68.67 \\
ADENINE & 6 & 4 & 2 & 5 & 4 & 2 & 39 & 4 & 4 & 48 & 1 & 5 \\
& 65.14 & 64.13 & 64.82 & 24.92 & 23.45 & 23.32 & 82.4 & 79.80 & 78.78 & 60.8 & 60.17 & 60.95 \\
CYTOSINE & 2 & 6 & 0 & 6 & 9 & 1 & 14 & 2 & 8 & 66 & 8 & 7 \\
& 79.28 & 78.17 & 78.87 & 29.50 & 28.19 & 28.83 & 88.3 & 85.34 & 86.81 & 74.4 & 88.31 & 74.20 \\
GUANINE & 2 & 6 & 9 & 5 & 1 & 3 & 17 & 7 & 3 & 36 & 7 & 5 \\
& 76.95 & 76.47 & 77.07 & 24.12 & 24.43 & 24.69 & 79.32 & 79.55 & 80.08 & 73.1 & 72.58 & 73.09 \\
THYMINE & 3 & 9 & 1 & 5 & 7 & 6 & 1 & 6 & 2 & 01 & 3 & 3 \\
\hline
\end{tabular}

\section{HOMO-LUMO ANALYSIS}

The highest occupied molecular orbitals and the lowest unoccupied molecular orbitals are abbreviated as HOMO and LUMO, respectively. They are also named as frontier molecular orbitals (FMO). The FMO have important roles in the electric and optical properties, as well as in quantum chemistry, chemical reactions and UV-VIS spectra. The HOMO containing electrons, represents the ability to donate an electron, whereas, LUMO have no electrons, as an electron acceptor represents the ability to occept an electron. There is an energy gap between HOMO and LUMO, and this energy gap determines the kinetic stability, chemical reactivity, optical polarizability and chemical hardness-softness of a molecule. It is high for hard molecules and is small for soft molecules. A small
HOMO-LUMO energy gap automatically means small excitation energies to the manifold of excited states. Therefore, soft molecules have small energy gap, will be more polarizable than hard molecules.

Kurşat and Yunus, 2014). The values of Homo-lumo energy gaps of Adenine at various levels of theory are listed in Table 5.The energy gaps were found as $11.6769 \mathrm{eV}$ at RHF/3-21G, 5.3488eV at B3LYP/3-21G, $3.4736 \mathrm{eV}$ at LSDA/3-21G and $11.6778 \mathrm{eV}$ at MP2/321G) for Adenine molecule. An observation of the other basis sets at various levels of theory shows that there is a very strong agreement between the values obtained by RHF and MP2 methods. It is also interesting to note that there is a strong agreement between experimental value and the value obtained at LSDA/3-21+G. 
BAJOPAS Volume 10 Number 1 June, 2017

Table 5: HOMO-LUMO Energy Gap of Adenine at Various Levels of Theory

\begin{tabular}{|c|c|c|c|c|c|c|}
\hline \multicolumn{2}{|c|}{ Method } & HOMO(a.u) & LUMO(a.u) & Eg(a.u) & $\mathrm{Eg}(\mathrm{eV})$ & $\begin{array}{l}\text { Preuss } \\
\text { et } a l, 2003\end{array}$ \\
\hline \multirow{5}{*}{ RHF } & $3-21 G$ & -0.31720 & 0.11191 & 0.42911 & 11.6769 & \multirow{16}{*}{$3.84 \mathrm{eV}$} \\
\hline & $3-21+G$ & -0.33413 & 0.05889 & 0.39302 & 10.6948 & \\
\hline & $6-31 G$ & -0.32338 & 0.10074 & 0.42412 & 11.5411 & \\
\hline & $6-31+G$ & -0.32970 & 0.05776 & 0.38746 & 10.5436 & \\
\hline & $3-21 G$ & -0.22167 & -0.02511 & 0.19656 & 5.3488 & \\
\hline \multirow{3}{*}{ B3LYP } & $3-21+G$ & -0.24781 & -0.05383 & 0.19398 & 5.2786 & \\
\hline & $6-31 G$ & -0.23081 & -0.03627 & 0.19454 & 5.2938 & \\
\hline & $6-31+G$ & -0.24393 & -0.05153 & 0.1924 & 5.2356 & \\
\hline \multirow{5}{*}{ LSDA } & $3-21 G$ & -0.20168 & -0.07403 & 0.12765 & 3.4736 & \\
\hline & $3-21+G$ & -0.23445 & -0.10225 & 0.1322 & 3.5974 & \\
\hline & $6-31 G$ & -0.21327 & -0.08582 & 0.12738 & 3.4662 & \\
\hline & $6-31+G$ & -0.23028 & -0.10036 & 0.12992 & 3.5353 & \\
\hline & $3-21 G$ & -0.31720 & 0.11194 & 0.42914 & 11.6778 & \\
\hline \multirow{3}{*}{ MP2 } & $3-21+G$ & -0.33413 & 0.05892 & 0.39305 & 10.6956 & \\
\hline & $6-31 G$ & -0.32339 & 0.10078 & 0.42417 & 11.5425 & \\
\hline & $6-31+G$ & -0.32971 & 0.05779 & 0.3875 & 10.5447 & \\
\hline
\end{tabular}

The values of Homo-lumo energy gaps of Cytosine at various levels of theory are listed in Table 6.The energy gaps were found as $10.4592 \mathrm{eV}$ at RHF/3$21+\mathrm{G}, 4.8467 \mathrm{eV}$ at $\mathrm{B} 3 \mathrm{LYP} / 3-21+\mathrm{G}, 3.3580 \mathrm{eV}$ at LSDA/3-21+G and $10.4576 \mathrm{eV}$ at MP2/3-21+G for cytosine molecule. An observation of the other basis sets at various levels of theory shows there is a very strong agreement between the values obtained by RHF and MP2 methods. However, the closest value to the experimental data is the value at LSDA/3-21G.

Table 6: HOMO-LUMO Energy Gap of Cytosine at Various Levels of Theory

\begin{tabular}{|c|c|c|c|c|c|c|}
\hline \multicolumn{2}{|c|}{ Method } & \multirow{2}{*}{$\begin{array}{l}\text { HOMO(a.u) } \\
-0.32048\end{array}$} & \multirow{2}{*}{$\begin{array}{l}\text { LUMO(a.u) } \\
0.09880\end{array}$} & Eg(a.u) & $\mathrm{Eg}(\mathrm{eV})$ & \multirow[t]{2}{*}{$\begin{array}{l}\text { Preuss } \\
\text { et al, } 2003\end{array}$} \\
\hline & $3-21 G$ & & & 0.41928 & 11.4094 & \\
\hline & $3-21+G$ & -0.34117 & 0.04319 & 0.38436 & 10.4592 & \\
\hline \multirow[t]{4}{*}{ RHF } & $6-31 G$ & -0.32880 & 0.08470 & 0.4135 & 11.2522 & \\
\hline & $6-31+G$ & -0.33556 & 0.04230 & 0.37786 & 10.2823 & \\
\hline & $3-21 G$ & -0.21728 & -0.03621 & 0.18107 & 4.9273 & \\
\hline & $3-21+G$ & -0.24614 & -0.06803 & 0.17811 & 4.8467 & \\
\hline \multirow[t]{4}{*}{ B3LYP } & $6-31 G$ & -0.22801 & -0.04959 & 0.17845 & 4.8560 & \\
\hline & $6-31+G$ & -0.24156 & -0.06520 & 0.17636 & 4.7991 & \\
\hline & $3-21 G$ & -0.20855 & -0.08365 & 0.1249 & 3.3988 & $3.64 \mathrm{eV}$ \\
\hline & $3-21+G$ & -0.23848 & -0.11508 & 0.1234 & 3.3580 & \\
\hline \multirow[t]{4}{*}{ LSDA } & $6-31 G$ & -0.22020 & -0.09754 & 0.12266 & 3.3378 & \\
\hline & $6-31+G$ & -0.23445 & -0.11275 & 0.1217 & 3.3117 & \\
\hline & $3-21 G$ & -0.32041 & 0.09887 & 0.41928 & 11.4094 & \\
\hline & $3-21+G$ & -0.34110 & 0.04320 & 0.3843 & 10.4576 & \\
\hline \multirow[t]{2}{*}{ MP2 } & $6-31 G$ & -0.32872 & 0.08480 & 0.41352 & 11.2527 & \\
\hline & $6-31+G$ & -0.33548 & 0.04231 & 0.37779 & 10.2804 & \\
\hline
\end{tabular}

The values of Homo-lumo energy gap of Guanine at various levels of theory are listed in Table 7.The energy gaps were found as $11.4930 \mathrm{eV}$ at $\mathrm{RHF} / 6-31 \mathrm{G}$, $5.2824 \mathrm{eV}$ at B3LYP/6-31G, 3.8064eV at LSDA/6-31G and $11.4933 \mathrm{eV}$ at MP2/6-31G for guanine molecule. An observation of the other basis sets at various levels of theory shows there is a very strong agreement between the values obtained by RHF and MP2 methods. It is highly interesting to note that the experimental value, $3.85 \mathrm{eV}$ is very close to the calculated value at LSDA/3-21G which is $3.8641 \mathrm{eV}$. 
BAJOPAS Volume 10 Number 1 June, 2017

Table 7: HOMO-LUMO Energy Gap of Guanine at Various Levels of Theory

\begin{tabular}{|c|c|c|c|c|c|c|}
\hline \multicolumn{2}{|c|}{ Method } & HOMO(a.u) & LUMO(a.u) & Eg(a.u) & Eg(eV) & $\begin{array}{c}\text { Preuss } \\
\text { et. al, } 2003\end{array}$ \\
\hline \multirow{5}{*}{ RHF } & $3-21 G$ & -0.29605 & 0.13106 & 0.42711 & 11.6225 & \multirow{16}{*}{$3.85 \mathrm{eV}$} \\
\hline & $3-21+G$ & -0.31651 & 0.04300 & 0.35951 & 9.7829 & \\
\hline & $6-31 G$ & -0.30523 & 0.11712 & 0.42235 & 11.4930 & \\
\hline & $6-31+G$ & -0.31179 & 0.04271 & 0.3545 & 9.6467 & \\
\hline & $3-21 G$ & -0.20387 & -0.00725 & 0.19662 & 5.3504 & \\
\hline \multirow{3}{*}{ B3LYP } & $3-21+G$ & -0.23301 & -0.04022 & 0.19279 & 5.2462 & \\
\hline & $6-31 G$ & -0.21508 & -0.02096 & 0.19412 & 5.2824 & \\
\hline & $6-31+G$ & -0.22882 & -0.03844 & 0.19038 & 5.1806 & \\
\hline \multirow{5}{*}{ LSDA } & $3-21 G$ & -0.19715 & -0.05515 & 0.142 & 3.8641 & \\
\hline & $3-21+G$ & -0.22763 & -0.08679 & 0.14084 & 3.8325 & \\
\hline & $6-31 G$ & -0.20946 & -0.06958 & 0.13988 & 3.8064 & \\
\hline & $6-31+G$ & -0.22400 & -0.08516 & 0.13884 & 3.7781 & \\
\hline & $3-21 G$ & -0.29599 & 0.13115 & 0.42714 & 11.6233 & \\
\hline \multirow{3}{*}{ MP2 } & $3-21+G$ & -0.31644 & 0.04297 & 0.35941 & 9.7803 & \\
\hline & $6-31 \mathrm{G}$ & -0.30515 & 0.11721 & 0.42236 & 11.4933 & \\
\hline & $6-31+G$ & -0.31178 & 0.04270 & 0.35448 & 9.6461 & \\
\hline
\end{tabular}

The values of Homo-lumo energy gaps of Thymine at various levels of theory are listed in Table 8.The energy gaps were found as $11.3193 \mathrm{eV}$ at RHF/6$31+\mathrm{G}, 5.3615 \mathrm{eV}$ at $\mathrm{B} 3 \mathrm{LYP} / 6-31+\mathrm{G}, 3.72864 \mathrm{eV}$ at LSDA/6-31+G and $11.3290 \mathrm{eV}$ at MP2/6-31+G for thymine molecule. An observation of the other basis sets at various levels of theory shows there is a very strong agreement between the values obtained by RHF and MP2 methods. The experimental value is approximately equal to the value obtained at LSDA/6$31 G$.

Table 8: HOMO-LUMO Energy Gap of Thymine at Various Levels of Theory

\begin{tabular}{|c|c|c|c|c|c|c|}
\hline \multicolumn{2}{|c|}{ Method } & HOMO(a.u) & LUMO(a.u) & Eg(a.u) & $\mathrm{Eg}(\mathrm{eV})$ & $\begin{array}{c}\text { Preuss } \\
\text { et } a l, 2003\end{array}$ \\
\hline \multirow{5}{*}{ RHF } & $3-21 G$ & -0.35755 & 0.09739 & 0.45494 & 12.3798 & \multirow{16}{*}{$3.76 \mathrm{eV}$} \\
\hline & $3-21+G$ & -0.37417 & 0.04734 & 0.42151 & 11.4701 & \\
\hline & $6-31 G$ & -0.36452 & 0.08301 & 0.44753 & 12.1781 & \\
\hline & $6-31+G$ & -0.36931 & 0.04666 & 0.41597 & 11.3193 & \\
\hline & $3-21 G$ & -0.24427 & -0.03968 & 0.20459 & 5.5673 & \\
\hline \multirow{3}{*}{ B3LYP } & $3-21+G$ & -0.27015 & -0.07123 & 0.19892 & 5.4130 & \\
\hline & $6-31 G$ & -0.25428 & -0.05372 & 0.20056 & 5.4576 & \\
\hline & $6-31+G$ & -0.26583 & -0.06880 & 0.19703 & 5.3615 & \\
\hline \multirow{5}{*}{ LSDA } & $3-21 G$ & -0.22544 & -0.08785 & 0.13759 & 3.7440 & \\
\hline & $3-21+G$ & -0.25806 & -0.11903 & 0.13903 & 3.7832 & \\
\hline & $6-31 \mathrm{G}$ & -0.24038 & -0.10234 & 0.13804 & 3.7563 & \\
\hline & $6-31+G$ & -0.25407 & -0.11705 & 0.13702 & 3.7286 & \\
\hline & $3-21 G$ & -0.35749 & 0.09745 & 0.45494 & 12.3798 & \\
\hline \multirow{3}{*}{ MP2 } & $3-21+G$ & -0.37415 & 0.04735 & 0.4215 & 11.4699 & \\
\hline & $6-31 G$ & -0.36444 & 0.08309 & 0.44753 & 12.1781 & \\
\hline & $6-31+G$ & -0.36923 & 0.04670 & 0.416323 & 11.3290 & \\
\hline
\end{tabular}

DIPOLE MOMENTS ( $\boldsymbol{\mu})$

The electric dipole moment is defined as $\mu=\mathrm{e} \times \mathrm{d}$ where $e$ is the magnitude of charge at either end of the dipole, and $d$ is the distance between the centres of + ve and - ve charge. The dipole moment is a vector quantity. It is used for determination of the type of a chemical bond (polar or covalent), molecular geometry (isomerism, valence angles etc.) mutual effects of atoms and properties of complexes and so on. It also reflects the electron density distribution in molecule in different states.

Dipole moment is expressed in Debye (D). In SI system the unit of dipole moment is $\mathrm{Cm}$ (coulomb $\times$ meter) where, $1 \mathrm{D}=3.334 \times 10^{-30} \mathrm{Cm}$. (Tridib and De, 2008).
Calculated Dipole Moments in each direction and Absolute Values (in Debye) of Adenine (A), Cytosine $(C)$, Guanine (G) and Thymine ( $T$ ) in Comparison with experimental data are listed in Tables 19, 20, 21 and 22 respectively.

Dipole Moments Of Adenine

It is interesting to note from Table 9 that there is an excellent agreement between the values of dipole moments obtained at each level of theory for adenine. There is also a good agreement between the calculated values and the experimental data values especially at the B3LYP/3-21G and LSDA/3-21G levels of theory with dipole moments of $2.5948 \mathrm{D}$ and $2.5508 \mathrm{D}$ respectively. 
BAJOPAS Volume 10 Number 1 June, 2017

Table 9: Dipole Moment of Adenine

\begin{tabular}{|c|c|c|c|c|c|c|}
\hline METHODS & BASIS SETS & $\mu_{\mathrm{x}}(\mathrm{D})$ & $\mu_{y}(D)$ & $\mu_{z}(D)$ & $\mu(D)$ & $\begin{array}{l}\text { Preuss, M } \\
\text { et } a /, 2003\end{array}$ \\
\hline \multirow{4}{*}{ RHF } & $3-21 G$ & 2.5645 & -0.5000 & 1.2062 & 2.8778 & \multirow{16}{*}{$2.5 \mathrm{eV}$} \\
\hline & $3-21+G$ & 2.8584 & -0.4113 & 1.1515 & 3.1090 & \\
\hline & $6-31 G$ & 2.7712 & -0.5153 & 1.2440 & 3.0811 & \\
\hline & $6-31+G$ & 2.8474 & -0.4604 & 1.0990 & 3.0867 & \\
\hline \multirow{5}{*}{ MP2 } & $3-21 G$ & 2.5645 & -0.5000 & 1.2062 & 2.8778 & \\
\hline & $3-21+G$ & 2.8584 & -0.4113 & 1.1515 & 3.1090 & \\
\hline & $6-31 G$ & 2.7712 & -0.5153 & 1.2440 & 3.0811 & \\
\hline & $6-31+G$ & 2.8474 & -0.4604 & 1.0990 & 3.0867 & \\
\hline & $3-21 G$ & 2.2144 & -0.8499 & 1.0523 & 2.5948 & \\
\hline \multirow[t]{4}{*}{ B3LYP } & $3-21+G$ & 2.6132 & -0.6748 & 1.0273 & 2.8878 & \\
\hline & $6-31 G$ & 2.4338 & -0.8144 & 1.0940 & 2.7899 & \\
\hline & $6-31+G$ & 2.6023 & -0.7123 & 0.9805 & 2.8707 & \\
\hline & $3-21 G$ & 2.0904 & -1.0256 & 1.0415 & 2.5508 & \\
\hline \multirow[t]{3}{*}{ LSDA } & $3-21+G$ & 2.5218 & -0.8184 & 1.0066 & 2.8359 & \\
\hline & $6-31 G$ & 2.3249 & -0.9710 & 1.0848 & 2.7431 & \\
\hline & $6-31+G$ & 2.5165 & -0.8527 & 0.9606 & 2.8253 & \\
\hline
\end{tabular}

Dipole Moments Of Cytosine

It can be seen from Table 10 that there is an excellent agreement between the values of dipole moment obtained at all levels of theory for cytosine. There is also a good agreement between the calculated values and the experimental data values especially at the B3LYP/3-21G and LSDA/3-21G levels of theory with dipole moments of $7.3229 \mathrm{D}$ and $7.4378 \mathrm{D}$ respectively.

Table 10: Dipole Moment of Cytosine

\begin{tabular}{|c|c|c|c|c|c|c|}
\hline METHODS & BASIS SETS & $\mu_{x}(D)$ & $\mu_{y}(D)$ & $\mu_{z}(D)$ & $\mu(D)$ & $\begin{array}{l}\text { Preuss M } \\
\text { et } a /, 2003\end{array}$ \\
\hline & $3-21 G$ & -7.7177 & -0.0329 & 1.4788 & 7.8582 & \\
\hline \multirow[t]{4}{*}{ RHF } & $3-21+G$ & -8.5103 & 0.4405 & 1.4445 & 8.6432 & \\
\hline & $6-31 G$ & -8.2918 & 0.2926 & 1.5350 & 8.4378 & \\
\hline & $6-31+G$ & -8.4111 & 0.3595 & 1.3900 & 8.5328 & \\
\hline & $3-21 G$ & -7.7177 & -0.0329 & 1.4788 & 7.8582 & \\
\hline \multirow[t]{4}{*}{ MP2 } & $3-21+G$ & -8.5103 & 0.4405 & 1.4445 & 8.6432 & \\
\hline & $6-31 G$ & -8.2918 & 0.2926 & 1.5350 & 8.4378 & \\
\hline & $6-31+G$ & -8.4111 & 0.3595 & 1.3900 & 8.5328 & $7.0 \mathrm{D}$ \\
\hline & $3-21 G$ & -7.1713 & -0.6632 & 1.3262 & 7.3229 & \\
\hline \multirow[t]{4}{*}{ B3LYP } & $3-21+G$ & -8.0642 & -0.0362 & 1.3274 & 8.1728 & \\
\hline & $6-31 G$ & -7.6924 & -0.3107 & 1.3887 & 7.8229 & \\
\hline & $6-31+G$ & -7.9705 & -0.1187 & 1.2811 & 8.0737 & \\
\hline & $3-21 G$ & -7.2613 & -0.9106 & 1.3285 & 7.4378 & \\
\hline \multirow[t]{3}{*}{ LSDA } & $3-21+G$ & -8.1261 & -0.2463 & 1.3199 & 8.2363 & \\
\hline & $6-31 G$ & -7.7595 & -0.5330 & 1.3937 & 7.9017 & \\
\hline & $6-31+G$ & -8.0367 & -0.3152 & 1.2745 & 8.1432 & \\
\hline
\end{tabular}

\section{Dipole Moments Of Guanine}

In the case of guanine it can be seen from Table 11 that there is an excellent agreement between the values of dipole moment obtained at each level of theory. There is also a good agreement between the calculated values and the experimental data values especially at the B3LYP/6-31G and LSDA/6-31G levels of theory with dipole moments of $7.2120 \mathrm{D}$ and 7.2280D respectively. 
BAJOPAS Volume 10 Number 1 June, 2017

Table 11: Dipole Moment of Guanine

\begin{tabular}{|c|c|c|c|c|c|c|}
\hline METHODS & BASIS SETS & $\mu_{\mathrm{x}}(\mathrm{D})$ & $\mu_{y}(D)$ & $\mu_{z}(D)$ & $\mu(D)$ & $\begin{array}{l}\text { Preuss } M \\
\text { et } a l, 2003\end{array}$ \\
\hline \multirow{5}{*}{ RHF } & $3-21 G$ & 3.5274 & -6.4608 & 1.3153 & 7.4776 & \\
\hline & $3-21+G$ & 3.4613 & -7.1024 & 1.2990 & 8.0070 & \\
\hline & $6-31 G$ & 3.4316 & -6.8636 & 1.3737 & 7.7956 & \\
\hline & $6-31+G$ & 3.4312 & -7.0015 & 1.2531 & 7.8971 & \\
\hline & $3-21 G$ & 3.5274 & -6.4608 & 1.3153 & 7.4776 & \\
\hline \multirow[t]{4}{*}{ MP2 } & $3-21+G$ & 3.4613 & -7.1024 & 1.2990 & 8.0070 & \\
\hline & $6-31 G$ & 3.4316 & -6.8636 & 1.3737 & 7.7956 & \\
\hline & $6-31+G$ & 3.4312 & -7.0015 & 1.2531 & 7.8971 & \\
\hline & $3-21 G$ & 3.4349 & -5.8843 & 1.1719 & 6.9135 & $7.1 \mathrm{D}$ \\
\hline \multirow[t]{4}{*}{ B3LYP } & $3-21+G$ & 3.2644 & -6.6482 & 1.1966 & 7.5024 & \\
\hline & $6-31 G$ & 3.3158 & -6.2831 & 1.2413 & 7.2120 & \\
\hline & $6-31+G$ & 3.2523 & -6.5599 & 1.1583 & 7.4130 & \\
\hline & $3-21 G$ & 3.5877 & -5.8501 & 1.1791 & 6.9632 & \\
\hline \multirow[t]{3}{*}{ LSDA } & $3-21+G$ & 3.3626 & -6.6046 & 1.1978 & 7.5075 & \\
\hline & $6-31 G$ & 3.4334 & -6.2362 & 1.2516 & 7.2280 & \\
\hline & $6-31+G$ & 3.3412 & -6.5166 & 1.1597 & 7.4145 & \\
\hline
\end{tabular}

Dipole Moments of Thymine calculated values and the experimental data especially In the case of thymine it can be seen from Table 12 that there is an excellent agreement between the values of dipole moment obtained at each level of theory. There is also a good agreement between the at the B3LYP/6-31G and LSDA/6-31+G levels of theory with dipole moments of $3.9730 \mathrm{D}$ and $4.2366 \mathrm{D}$ respectively.

\begin{tabular}{|c|c|c|c|c|c|c|}
\hline METHODS & BASIS SETS & $\mu_{x}(D)$ & $\mu_{\mathrm{y}}(\mathrm{D})$ & $\mu_{z}(D)$ & $\mu(D)$ & $\begin{array}{l}\text { Preuss M } \\
\text { et al,2003 }\end{array}$ \\
\hline \multirow{4}{*}{ RHF } & $3-21 G$ & -1.5520 & -3.7302 & 1.3910 & 4.2729 & \\
\hline & $3-21+G$ & -1.9075 & -4.3863 & 1.3197 & 4.9619 & \\
\hline & $6-31 G$ & -1.8104 & -4.0887 & 1.4219 & 4.6923 & \\
\hline & $6-31+G$ & -1.8302 & -4.3019 & 1.2833 & 4.8480 & \\
\hline \multirow{4}{*}{ MP2 } & $3-21 G$ & -1.5520 & -3.7302 & 1.3910 & 4.2729 & \\
\hline & $3-21+G$ & -1.9075 & -4.3863 & 1.3197 & 4.9619 & \\
\hline & $6-31 G$ & -1.8104 & -4.0887 & 1.4219 & 4.6923 & \\
\hline & $6-31+G$ & -1.8302 & -4.3019 & 1.2833 & 4.8480 & \\
\hline \multirow{3}{*}{ B3LYP } & $3-21 G$ & -1.1522 & -3.0752 & 1.2490 & 3.5134 & $4.1 \mathrm{D}$ \\
\hline & $3-21+G$ & -1.6859 & -3.8970 & 1.2042 & 4.4135 & \\
\hline & $6-31 G$ & -1.4488 & -3.4705 & 1.2811 & 3.9730 & \\
\hline \multirow{5}{*}{ LSDA } & $6-31+G$ & -1.6081 & -3.8284 & 1.1769 & 4.3159 & \\
\hline & $3-21 G$ & -1.1096 & -2.9407 & 1.2679 & 3.3892 & \\
\hline & $3-21+G$ & -1.6703 & -3.7963 & 1.2067 & 4.3195 & \\
\hline & $6-31 G$ & -1.4269 & -3.3559 & 1.2983 & 3.8709 & \\
\hline & $6-31+G$ & -1.6007 & -3.7403 & 1.1817 & 4.2366 & \\
\hline
\end{tabular}

POLARIZABILITY

Polarizability is the ability of a molecule to be polarized. Polarizabilities determine the dynamical response of a bound system to external fields and provide insight into a molecule's internal structure. It can be defined as the ratio of induced dipole moment of an atom to the electric field that produces this dipole moment. Polarizability, a, tells us how easy is to disturb charge distribution, like the electron cloud of an atom or molecule, from its normal shape by an external electric field. In general, larger molecules are more easily polarizable than smaller ones. Polarizability has the S.I. units of $\mathrm{Cm}^{2} \mathrm{~V}^{-1}$. In this work the mean polarizabilities of the molecules were calculated from the polarizability components as $\langle\mathrm{a}\rangle=\frac{1}{3}\left(\mathrm{a}_{x x}+\mathrm{a}_{y y}+\mathrm{a}_{z z}\right)$

(7)

The polarizability was calculated using RHF, DFT and MP2 methods with 3-21G basis set.

Table 13: The mean polarizabilities of adenine molecule

\begin{tabular}{ccccccccc}
\hline & \multicolumn{7}{c}{ PARAMETERS } \\
BASIS SETS & $\mathrm{a}_{\mathrm{xx}}(\mathrm{a} . \mathrm{u})$ & $\mathrm{a}_{\mathrm{xy}}(\mathrm{a} . \mathrm{u})$ & $\mathrm{a}_{\mathrm{xz}}(\mathrm{a} . \mathrm{u})$ & $\mathrm{a}_{\mathrm{yy}}(\mathrm{a} . \mathrm{u})$ & $\mathrm{a}_{\mathrm{yz}}(\mathrm{a} . \mathrm{u})$ & $\mathrm{a}_{\mathrm{zz}}(\mathrm{a} . \mathrm{u})$. & $\mathrm{a}_{\mathrm{tot}}(\mathrm{a} . \mathrm{u})$ & e.s.u. $\left(\times 10^{-24}\right)$ \\
\cline { 2 - 10 } RHF/3-21G & 99.398 & -1.384 & -0.280 & 80.161 & -0.248 & 21.590 & 67.040 & 9.9 \\
MP2/3-21G & 101.474 & -1.537 & -0.013 & 86.596 & 0.126 & 22.317 & 70.129 & 10.393 \\
B3LYP/321G & 106.694 & -1.496 & -0.055 & 87.178 & 0.035 & 22.880 & 72.251 & 10.706 \\
LSDA/3-21G & 109.184 & -1.413 & 0.016 & 89.235 & 0.121 & 23.342 & 73.920 & 10.955 \\
\hline
\end{tabular}


BAJOPAS Volume 10 Number 1 June, 2017

Table 14: The mean polarizabilities of cytosine molecule

\begin{tabular}{ccccccccc}
\hline \multirow{2}{*}{ BASIS SETS } & \multirow{2}{*}{$\mathrm{a}_{\mathrm{xx}}$ (a.u.) } & \multirow{2}{*}{$\mathrm{a}_{\mathrm{xy}}$ (a.u.) } & $\mathrm{a}_{\mathrm{xz}}$ (a.u.) & $\mathrm{a}_{\mathrm{yy}}$ (a.u.) & $\mathrm{a}_{\mathrm{yz}}($ a.u. $)$ & $\mathrm{a}_{\mathrm{zz}}$ (a.u.) & $\mathrm{a}_{\mathrm{tot}}$ (a.u.) & \multicolumn{2}{c}{ e.s.u. $\left(\times 10^{-}\right.$} \\
& & & & & & & & \\
\hline RHF/3-21G & 73.307 & -2.912 & -0.532 & 67.204 & -0.884 & 17.016 & 52.509 & 7.782 \\
MP2/3-21G & 80.199 & -1.382 & -0.328 & 70.226 & -0.730 & 17.659 & 56.028 & 8.303 \\
B3LYP/321G & 80.171 & -0.996 & -0.279 & 70.577 & -0.716 & 18.164 & 56.304 & 8.344 \\
LSDA/3-21G & 82.607 & -0.364 & -0.183 & 71.635 & -0.635 & 18.576 & 57.606 & 8.537 \\
\hline
\end{tabular}

Table 15: The mean polarizabilities of guanine molecule

\begin{tabular}{ccccccccc}
\hline \multirow{2}{*}{ BASIS SETS } & $\mathrm{a}_{\mathrm{xx}}$ (a.u.) & $\mathrm{a}_{\mathrm{xy}}$ (a.u.) & $\mathrm{a}_{\mathrm{xz}}$ (a.u.) & $\mathrm{a}_{\mathrm{yy}}$ (a.u.) & $\mathrm{a}_{\mathrm{yz}}($ a.u. $)$ & $\mathrm{a}_{\mathrm{zz}}$ (a.u.) & $\mathrm{a}_{\mathrm{tot}}$ (a.u.) & \multicolumn{2}{c}{ e.s.u. $\left(\times 10^{-}\right.$} \\
& & & & & & & & \\
\hline RHF/3-21G & 98.502 & 4.693 & 1.860 & 81.244 & 0.990 & 23.676 & 67.807 & 10.049 \\
MP2/3-21G & 107.327 & 3.032 & 1.678 & 83.489 & 1.006 & 24.356 & 71.724 & 10.629 \\
B3LYP/321G & 112.904 & 3.245 & 1.706 & 84.868 & 1.024 & 24.934 & 74.235 & 11.002 \\
LSDA/3-21G & 117.469 & 2.642 & 1.587 & 86.183 & 1.019 & 25.360 & 76.337 & 11.313 \\
\hline
\end{tabular}

Table 16: The mean polarizabilities of thymine molecule

\begin{tabular}{ccccccccc}
\hline & \multicolumn{7}{c}{ PARAMETERS } \\
BASIS SETS & $\mathrm{a}_{\mathrm{xx}}$ (a.u.) & $\mathrm{a}_{\mathrm{xy}}($ a.u. $)$ & $\mathrm{a}_{\mathrm{xz}}($ a.u. $)$ & $\mathrm{a}_{\mathrm{yy}}($ a.u. $)$ & $\mathrm{a}_{\mathrm{yz}}($ a.u. $)$ & $\mathrm{a}_{\mathrm{zz}}($ a.u. $)$ & $\mathrm{a}_{\mathrm{tot}}($ a.u. $)$ & e.s.u $\left(\times 10^{-24}\right)$ \\
\hline RHF/3-21G & 79.036 & -9.067 & 0.743 & 65.556 & -0.970 & 26.784 & 57.125 & 8.466 \\
MP2/3-21G & 82.716 & -5.911 & 0.736 & 65.904 & -0.909 & 27.107 & 58.576 & 8.669 \\
B3LYP/321G & 85.745 & -5.904 & 0.744 & 68.457 & -0.916 & 27.636 & 60.613 & 8.983 \\
LSDA/3-21G & 88.778 & -4.712 & 0.688 & 69.652 & -0.857 & 28.031 & 62.154 & 9.21 \\
\hline
\end{tabular}

The mean polarizabilities of each of the molecules are listed in Tables 13-16 respectively. It can be seen from the Tables that there is a strong agreement between the values of the polarizabilities at all levels of theory. Also, in each of the molecules the value of polarizability increases from the lowest value at RHF to the highest value at DFT/LSDA. For example, the lowest value of polarizability of adenine molecule which is 67.040 a.u. was obtained at RHF/3-21G and the highest value, 73.920 a.u. was at the LSDA/321G. A similar trend is observed in the case of thymine molecule. The lowest value of polarizability of thymine molecule which is 57.125 a.u. was obtained at RHF/3-21G and the highest value, 62.154 a.u. was at the LSDA/3-21G.

It is interesting to note that guanine, the largest of the four molecules has the highest polarizability at all levels of theory while cytosine, the smallest has the lowest values. This is in conformity with the fact that larger molecules are more easily polarizable than smaller ones.

\section{MULLIKEN ATOMIC CHARGES}

The Mulliken atomic charge in any molecule is directly related to their vibrational properties and quantifies how the electronic structure changes under atomic displacement. Therefore, it is directly related to the chemical bonds present in the molecule. It affects many parameters of the molecule such as its dipole moment, polarizability, electronic structure and more properties of molecular system (Ramalingam et al, 2012).

The total atomic charges of adenine, cytosine, guanine and thymine obtained by Mulliken population analysis with RHF/ 6-31+G, DFT (B3LYP and LSDA)6$31+\mathrm{G}$ and $\mathrm{MP} 2 / 6-31+\mathrm{G}$ methods are listed in Tables $17-20$ respectively.

Table 17 Mulliken Atomic Charges of Adenine

\begin{tabular}{cccccc}
\hline & & \multicolumn{4}{c}{ Atomic } \\
Atomic No. & Atom & RHF & B3LYP & LSDA & MP2 \\
\hline 1 & N & -0.840457 & -0.617891 & -0.545600 & -0.840457 \\
2 & $\mathrm{C}$ & 0.303929 & 0.206418 & 0.123657 & 0.303929 \\
3 & $\mathrm{~N}$ & -0.370795 & -0.361223 & -0.319001 & -0.370795 \\
4 & $\mathrm{C}$ & -0.000971 & 0.146980 & 0.236467 & -0.000971 \\
5 & $\mathrm{C}$ & 0.137356 & 0.011725 & -0.113162 & 0.137356 \\
6 & $\mathrm{C}$ & 0.246211 & 0.126381 & 0.039677 & 0.246211 \\
7 & $\mathrm{H}$ & 0.484964 & 0.410353 & 0.417490 & 0.484964 \\
8 & $\mathrm{C}$ & 0.227963 & 0.104495 & -0.067694 & 0.227963 \\
9 & $\mathrm{~N}$ & -0.761116 & -0.628948 & -0.575998 & -0.761116 \\
10 & $\mathrm{~N}$ & -0.425948 & -0.321096 & -0.253668 & -0.425948 \\
11 & $\mathrm{H}$ & 0.408719 & 0.373145 & 0.383203 & 0.408719 \\
12 & $\mathrm{H}$ & 0.394165 & 0.365107 & 0.377759 & 0.394165 \\
13 & $\mathrm{~N}$ & -0.321252 & -0.231195 & -0.162162 & -0.321252 \\
14 & $\mathrm{H}$ & 0.275671 & 0.220171 & 0.241443 & 0.275671 \\
15 & $\mathrm{H}$ & 0.241559 & 0.195579 & 0.217589 & 0.241559 \\
\hline
\end{tabular}


BAJOPAS Volume 10 Number 1 June, 2017

It is observed from Table 17 that the charge distribution varies with the computational method. For example, the charge of C4 atom is -0.000971 for RHF and MP2 levels, 0.146980 for B3LYP level and 0.236467 for LSDA level. It is also noted that all the five hydrogen atomic charges obtained by DFT method are smaller than those calculated by RHF and MP2 methods. All the hydrogen atoms charges are positive. Obviously, the charge on $\mathrm{H} 7$ atom is bigger than those on other hydrogen atoms at all levels. The charge on $\mathrm{H} 7$ atom is 0.484964 at RHF and MP2 levels while it is 0.410353 at B3LYP and 0.417490 at
LSDA. The charge on all nitrogen atoms at all levels are negative. The charges on all the nitrogen atoms increase from RHF and MP2 methods to DFT method. For example, the charges on $\mathrm{N} 1$ and N3 atoms increase from RHF and MP2 levels to DFT level and they are -0.545600 and -0.319001 at LSDA. From the above analysis, we can conclude that the higher charge on $\mathrm{H} 7$ and the lower charge on N1 may suggest the formation of intramolecular attraction. From the data it is also clear that all the hydrogen atoms act as charge donors.

Table 18: Mulliken Atomic Charges of Cytosine

\begin{tabular}{cccccc}
\hline & & & \multicolumn{4}{c}{ Atomic } & Charges \\
Atomic No. & Atom & RHF & B3LYP & LSDA & MP2 \\
\hline 1 & $\mathrm{~N}$ & -0.827942 & -0.582388 & -0.500508 & -0.827942 \\
2 & $\mathrm{C}$ & 0.262029 & 0.160965 & -0.025125 & 0.262029 \\
3 & $\mathrm{~N}$ & -0.358162 & -0.225438 & -0.144604 & -0.358162 \\
4 & $\mathrm{C}$ & 0.643926 & 0.367097 & 0.237108 & 0.643926 \\
5 & $\mathrm{O}$ & -0.606860 & -0.472637 & -0.418811 & -0.606860 \\
6 & $\mathrm{~N}$ & -0.820199 & -0.718975 & -0.685214 & -0.820199 \\
7 & $\mathrm{H}$ & 0.383748 & 0.352835 & 0.365578 & 0.383748 \\
8 & $\mathrm{C}$ & 0.020331 & 0.161442 & 0.261728 & 0.020331 \\
9 & $\mathrm{C}$ & -0.082172 & -0.195624 & -0.297960 & -0.082172 \\
10 & $\mathrm{H}$ & 0.487257 & 0.410030 & 0.414823 & 0.487257 \\
11 & $\mathrm{H}$ & 0.396446 & 0.365862 & 0.377313 & 0.396446 \\
12 & $\mathrm{H}$ & 0.249622 & 0.196483 & 0.216456 & 0.249622 \\
13 & $\mathrm{H}$ & 0.251976 & 0.180349 & 0.199216 & 0.251976 \\
\hline
\end{tabular}

It is observed from Table 18 that the charge distribution depends on the computational method. For example, the charge of C2 atom is 0.262029 for RHF and MP2 levels, 0.160965 for B3LYP level and 0.025125 for LSDA level. It is also interesting to note, from Table 18 that all the hydrogen atoms in cytosine have positive charges, while negative charges are noticed for the nitrogen atoms at all levels of theory. The charges on oxygen atoms at all levels of theory are negative.
Obviously, the charge on $\mathrm{H} 10$ atom is bigger than those on other hydrogen atoms at all levels. The charges on $\mathrm{H} 10$ atom are bigger than those on all other hydrogen atoms. They are 0.487257 at RHF and MP2 levels while they are 0.410353 at B3LYP and 0.417490 at LSDA. The lower charges on N1 atom may suggest intramolecular attraction between $\mathrm{H} 10$ atom and N1 atom. From the data it is clear that all the hydrogen atoms act as charge donors.

Table 19: Mulliken Atomic Charges of Guanine

\begin{tabular}{|c|c|c|c|c|c|}
\hline \multirow[b]{2}{*}{ Atomic No. } & \multirow[b]{2}{*}{ Atom } & \multicolumn{4}{|c|}{ Atomic Charges } \\
\hline & & RHF & B3LYP & LSDA & MP2 \\
\hline 1 & $\mathrm{~N}$ & -0.816337 & -0.600438 & -0.531146 & -0.816337 \\
\hline 2 & C & 0.395043 & 0.302683 & 0.232937 & 0.395043 \\
\hline 3 & C & 0.357537 & 0.201750 & 0.116267 & 0.357537 \\
\hline 4 & $\mathrm{H}$ & 0.497903 & 0.418220 & 0.423447 & 0.497903 \\
\hline 5 & $\mathrm{~N}$ & -0.300485 & -0.290918 & -0.235699 & -0.300485 \\
\hline 6 & C & -0.143168 & 0.046233 & 0.073900 & -0.143168 \\
\hline 7 & $\mathrm{~N}$ & -0.465404 & -0.340773 & -0.248996 & -0.465404 \\
\hline 8 & $\mathrm{H}$ & 0.268204 & 0.211934 & 0.233222 & 0.268204 \\
\hline 9 & C & 0.652617 & 0.380775 & 0.222929 & 0.652617 \\
\hline 10 & C & 0.598139 & 0.322810 & 0.145042 & 0.598139 \\
\hline 11 & 0 & -0.645937 & -0.521374 & -0.463553 & -0.645937 \\
\hline 12 & $\mathrm{~N}$ & -0.913312 & -0.639079 & -0.546713 & -0.913312 \\
\hline 13 & $\mathrm{~N}$ & -0.809270 & -0.661594 & -0.617114 & -0.809270 \\
\hline 14 & $\mathrm{H}$ & 0.506779 & 0.423377 & 0.425166 & 0.506779 \\
\hline 15 & $\mathrm{H}$ & 0.439140 & 0.397194 & 0.406930 & 0.439140 \\
\hline 16 & $\mathrm{H}$ & 0.378553 & 0.349200 & 0.363381 & 0.378553 \\
\hline
\end{tabular}


It is observed from Table 19 that the charge distribution is related to the computational method used. For example, the charge of $\mathrm{C} 6$ atom is 0.143168 for RHF and MP2 levels, 0.046233 for B3LYP level and 0.073900 for LSDA level. It is also noted that all the five hydrogen atomic charges obtained by DFT method are smaller than those calculated by RHF and MP2 methods. It is interesting to mention also that all the charges are positive. It is observed that the charge on $\mathrm{H} 14$ atom is bigger than those on other hydrogen atoms at all levels. The charge on $\mathrm{H} 14$ atom is 0.506779 at RHF and MP2 levels while it is
0.423377 at B3LYP and 0.425166 at LSDA. The charge on all nitrogen atoms at all levels are negative. The charges increase from RHF and MP2 methods to DFT method. For example, the charges on $\mathrm{N} 1$ and $\mathrm{N} 12$ atoms increase from RHF and MP2 levels to DFT level and they are -0.639079 at B3LYP and -0.546713 at LSDA. From the above analysis, we can conclude that the higher charge on $\mathrm{H} 14$ and the lower charge on N12 may suggest the formation of intramolecular attraction. From the data it is also clear that all the hydrogen atoms act as charge donors.

Table 20 Mulliken Atomic Charges of Thymine

\begin{tabular}{cccccc}
\hline & & \multicolumn{4}{c}{ Atomic Charges } \\
Atomic No. & Atom & RHF & B3LYP & LSDA & MP2 \\
\hline 1 & $\mathrm{~N}$ & -0.705667 & -0.508037 & -0.433870 & -0.705667 \\
2 & $\mathrm{C}$ & 0.870905 & 0.542588 & 0.399801 & 0.870905 \\
3 & $\mathrm{C}$ & -0.482063 & -0.559532 & -0.583573 & -0.482063 \\
4 & $\mathrm{H}$ & 0.446958 & 0.407573 & 0.421728 & 0.446958 \\
5 & $\mathrm{O}$ & -0.596532 & -0.475277 & -0.424197 & -0.596532 \\
6 & $\mathrm{~N}$ & -0.893915 & -0.587859 & -0.482308 & -0.893915 \\
7 & $\mathrm{C}$ & 1.075150 & 1.128252 & 1.083817 & 1.075150 \\
8 & $\mathrm{H}$ & 0.280348 & 0.219386 & 0.238355 & 0.280348 \\
9 & $\mathrm{C}$ & 0.444555 & 0.338552 & 0.239098 & 0.444555 \\
10 & $\mathrm{C}$ & -1.000925 & -1.095445 & -1.201297 & -1.000925 \\
11 & $\mathrm{H}$ & 0.525505 & 0.442086 & 0.444978 & 0.525505 \\
12 & $\mathrm{O}$ & -0.621019 & -0.503787 & -0.454053 & -0.621019 \\
13 & $\mathrm{H}$ & 0.192867 & 0.187392 & 0.218265 & 0.192867 \\
14 & $\mathrm{H}$ & 0.231397 & 0.231705 & 0.266297 & 0.231397 \\
15 & $\mathrm{H}$ & 0.232433 & 0.232402 & 0.266960 & 0.232433 \\
\hline
\end{tabular}

It is observed from Table 20 that the charge distribution depends on the computational method. For example, the charge of 05 atom is -0.596532 for RHF and MP2 levels, -0.475277 for B3LYP level and 0.424197 for LSDA level. It is also interesting to note from Table 20, that all the hydrogen atoms in thymine have positive charges, while negative charges are noticed for the nitrogen and oxygen atoms at all levels of theory. Obviously, the charge on $\mathrm{H} 11$ atom is bigger than those on other hydrogen atoms at all levels. It is 0.487257 at RHF and MP2 levels while it is 0.442086 at B3LYP and 0.444978 at LSDA. The charges on $C 2, C 7$ and $C 9$ are all positive while the charge on $\mathrm{C} 3$ and $\mathrm{C} 10$ are all negative at all levels of theory.

\section{CONCLUSION}

Thermodynamic parameters, HOMO-LUMO energy gaps, dipole moments and polarizability of each of the molecules were calculated at RHF, MP2and DFT(B3LYP and LSDA) levels of theory utilizing 321G,3-21+G,6-31G AND 6-31+G basis sets. Some thermodynamic properties of the molecules were computed and reported. The results agreed with the different levels of theory and basis sets used. A reasonable agreement was observed between the calculated homo-lumo energy gaps of the molecules and the experimental values. The Mullikan atomic charges, polarizabilities and dipole moments of the molecules are also reported. Polarizability shows how easy it is to form a dipole moment. This fact has been confirmed by the result obtained in this work. Guanine which has the highest polarizability also has the highest dipole moment. The observed spectra are in very good agreement for RHF, MP2 and DFT methods. In general, the calculations obtained at the DFT level gave a better agreement with the experimental values. The entire work was performed in gas phase. It is recommended that this work should be carried out in any suitable solvent in order to give further insight into the nature and properties of these molecules.

\section{RECOMMENDATIONS}

The authors recommend that other levels of theory and higher basis sets should be used to carry out the computations. Another molecular modelling tool can also be used to perform all the calculations and also to compute vibrational frequencies of the molecules. Comparison should be made with this work.

\section{CONTRIBUTIONS OF AUTHORS}

A. S Gidado initiated the work, provided some relevant journals and performed the thermodynamic calculations. Salihu Abubakar carried out the calculations for HOMO-LUMO and dipole moments while M. A Shariff did the computations for polarizability and Mulliken atomic charges. We all took part in the compilation and interpretations of the results as well as the proof reading of the entire write up. 


\section{ACKNOWLEDGEMENT}

The authors wish to thank Dr. Chifu E. Ndikilar of the department of Physics, Federal University Dutse,

\section{REFERENCES}

Bryce, C. F.A and Pacini, D (1998). The Structure and Function of Nucleic Acids. Bolton: Biochemical Society.

Espejo, C. and Gonzalez, R. (2007). Stabilization and Interaction Energies of Non-Polar DNA Base Pairs: Guanine-Cytosine and AdenineThymine: A Study Based on the SIESTA Method.53 (7):212-216.

Feng, Z., Chen, L., Maddula, H., Akan, O., Oughtred, R., Bermann, H. and Westbrook, J. (2004). Ligand Depot: A Data warehouse for Ligands Bound to Macromolecules: Bioinformatics 1:20(13):2153-5

Gang, Z. and Charles, B. (2007). Comparison of DFT Methods for Molecular Orbital Eigenvalue Calculations, Journals of Physical Chemistry, 111(8):1554-1561

Hobza, P., Kabelac, M., Mejzlik, P. and Vondrasek, J. (1997). Journal of Computational Chemistry.18:1136

Keith, D. and Vitaly, V. (1997). Electric-Dipole Polarizabilities of Atoms, Molecules and Clusters. Singapore: World Scientific Publishing Company

Kurşat, E and Yunus, B. (2014). Theoretical and Experimental Investigations on Molecular Structure, IR, NMR Spectra and HOMOLUMO Analysis of 4-Methoxy- $N$-(3Phenylallylidene) Aniline. American Journal of Physical Chemistry, 3 (2):19-25.
Jigawa state for providing them with the Guassian 03 package.

Neidle, S (1994). DNA Structure and Recognition.Oxford:Oxford University Press. PP 87-90

Neuman R. C. (1999). Nucleic Acids from Organic Chemistry. California: University of California pp 3-8

Preuss, M. S. S. and Bechstedt, F. (2004). Groundand Excited-State Properties of DNA Base, Journal of Computational Chemistry 25: PP $112-122$

Ramalingam, S., Karabacak, M., Periandy, S., Puviarasan, N and Tanuja, D. (2012). Spectroscopic (infrared, Raman, UV and NMR) analysis, Gaussian hybrid computational investigation (MEP maps/HOMO and LUMO) on cyclohexanone oxime, Spectrochimica Acta Part A: Molecular and Biomolecular Spectroscopy, 96 (2012) 207-220.

Robert, J., Van, M. and Tanja, G. (2002). A Critical Note on Density Functional Theory Studies on Rare-gas Dimers", Journal of Chemical Physics 116(22):9620-9623.

Shishkin, O., Gorb, L., Hobza, P. and Leszczynski, J. (2008). International Journal of Quantum Chemistry.80:1116 